providers. We continued bi-weekly chart audits for appropriate referrals being placed for 12 months.

Results As of August 2020, we were able to meet our goal at $42 \%$ with 1,813 referrals placed for DSME. Of these, 1,086 patients completed their education sessions (figure 1).

Conclusions Quality improvement tools and methodologies can be successfully utilized to improve care for diabetes in clinical settings. We were able to create a process that has maintained success, even during the uncertain times of COVID-19. The processes created and put in place were sustainable and have allowed the staff to continue placing referrals during telehealth visits and patients completing DSME virtually.

\section{DECREASING NEONATAL JAUNDICE READMISSION RATES THROUGH IMPLEMENTATION OF A JAUNDICE MANAGEMENT GUIDE}

${ }^{1}$ Laura Hunt, ${ }^{1}$ Marie Ramos, ${ }^{1} Y$ vonne Helland, ${ }^{2}$ Karen Lamkin. ${ }^{1}$ Baylor Scott and White Health, USA; ${ }^{2}$ Baylor Scott and White at Waxahachie, USA

\subsection{6/bmjoq-2020-|HI.19}

Background Baylor Scott and White Medical Center at Waxahachie (BSWMCW), a level 1 neonatal designated facility, had rising neonatal jaundice readmission rates for two fiscal years $(1.7 \%-2.6 \%)$. Based off literature review, this was above the average rate for hospitals with similar populations $(0.5 \%-2.0 \%)$. Neonatal jaundice readmissions have several effects on families and the neonate related to increased costs, stress on bonding, and increased risk for hospital acquired infections.
Objectives By June 30, 2019, BSWMCW will reduce the rolling neonatal jaundice readmission rate from $2.6 \%$ (July 1, 2017-June 30, 2018) to less than 1\% (July 1, 2018 - June 30, 2019).

Methods A multidisciplinary committee met to identify why excessive neonatal jaundice readmissions occurred. Issues identified were inconsistent practices in starting and stopping phototherapy, timing of discharge, and timing of newborn follow up in infants with jaundice (figure 1). The team prioritized management of jaundice through recognizing plan of care modifications during the initial hospitalization which would impact newborn readmission rates. Initially, clear guidelines were created on when to start or stop phototherapy, including discharge criteria, followed by implementation of new supplementation guidelines. Donor milk was offered as an alternative to formula supplementation. In order to adhere to supplementation guidelines, standardized newborn weights at 24 hours of life was added. Finally, jaundice lab testing was required through BSWMCW inpatient lab prior to admission rather

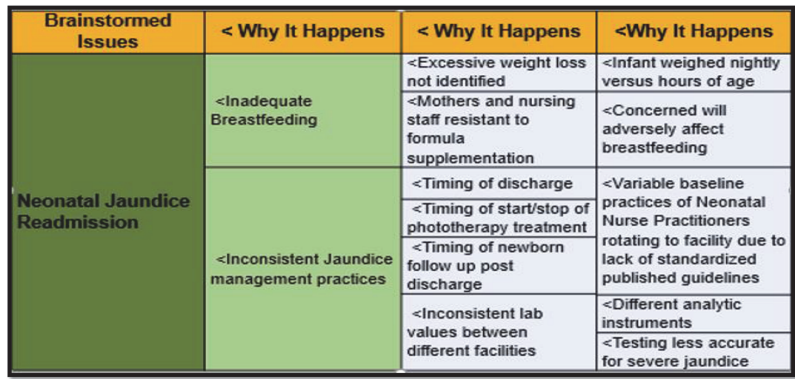

Abstract 19 Figure 1

Decreasing Neonatal Jaundice Readmission Rates Through Implementation Of A Jaundice Management Guide

\begin{tabular}{|c|c|}
\hline & JAUNDICE MANAGEMENT GUIDE \\
\hline \multicolumn{2}{|r|}{ Indications to Start Phototherapyfor Inpatients } \\
\hline \multicolumn{2}{|c|}{ 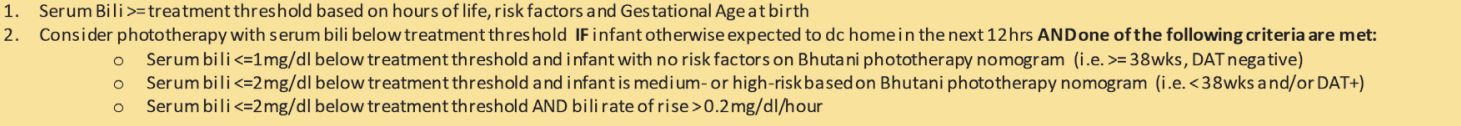 } \\
\hline \multicolumn{2}{|r|}{ How to Provide Phototherapy } \\
\hline Bilirubin Level & Treatment \\
\hline Below treatment threshold & ○ Biliblanket \\
\hline At threshold & - bili blanket $+/$ - overhead light, depending on rate of rise, risk factors, target day of dc, etc. \\
\hline Above trea tment threshold & Biliblanket and at least one overhead light \\
\hline Bili within $3-4 \mathrm{mg} / \mathrm{dl}$ of threshold for exchange transfusion & Biliblanket and at least two overhead lights \\
\hline Bili $>=3$ of treatment & $\begin{array}{l}3 \text { total lights needed ((i.e. blanket and double bank overhead) and/or infant needing IVF and/or any } \\
\text { concerns for poor parental compliance with trea tment: trea tment should occur physically in intermediate } \\
\text { carenursery) }\end{array}$ \\
\hline \multicolumn{2}{|c|}{$\begin{array}{l}\text { *Outpati ent phototherapy can be considered ONLY if no riskfactors are pres ent (i.e. full term, no ABO set-up, etc.), feeding is going well a nd fa mily is reliable with good a ccess to } \\
\text { care }\end{array}$} \\
\hline \multicolumn{2}{|c|}{ Stopping Phototherapy } \\
\hline Estimated Gestational Age $>=38$ weeks at birth & - Serum bili $>=3 \mathrm{mg} / \mathrm{dl} \mathrm{bel} \mathrm{ow} \mathrm{trea} \mathrm{tment} \mathrm{threshold} \mathrm{for} \mathrm{current} \mathrm{hours} \mathrm{of} \mathrm{life}$ \\
\hline Estimated Gestational Age $<38$ weeks at birth & - Serum bili $>=4 \mathrm{mg} / \mathrm{dl}$ bel ow treatment threshold for current hours of life \\
\hline \multicolumn{2}{|c|}{$\begin{array}{l}\text { Schedule follow-up within } 24 \text { hrs if bili is high inter mediate risk and continuing to rise and/or if infant has persistent feeding difficulties (i.e. excessive weight loss, not latching } \\
\text { well, etc.) associated with jaundice; otherwise follow-up should be scheduled within } 48 \text { hours. } \\
\text { Determining Readiness for Discharge }\end{array}$} \\
\hline \multirow{2}{*}{\multicolumn{2}{|c|}{$\begin{array}{l}\text { 1. Recheck rum bili 6-8hrs after stopping phototherapy } \\
\circ \quad \text { Bili should rebound }<2 \mathrm{mg} / \mathrm{dl} \text { from previous bili and remain at least } 3 \mathrm{mg} / \mathrm{dl} \text { bel ow trea tment threshold for current hours of life } \\
\text { 2. Consider holding discharge and/or staring phototherapy IF: } \\
0 \text { Bil i is high risk } \\
\text { OR } \\
0 \text { Bili i s high intermediate risk with rate of rise }>0.2 \mathrm{mg} / \mathrm{dl} / \mathrm{hr}, \text {, particularly if infant is medium or high risk on Bhutani curve. } \\
\text { Indications to Supplement Breastfeeding Infants with High Intermediate or High Risk Bili }\end{array}$}} \\
\hline & \\
\hline $\begin{array}{l}\text { One or more of the Following: } \\
\begin{array}{ll}\text { o } & \text { weight loss }>75^{\text {th }} \% \text { for age on NEWT calculator (newb } \\
\circ & \text { poor skin turgor, drymucus membranes, sunken fonta } \\
0 & \text { decreased output }(\text { fewer voids } / \text { stools than number of } \\
0 & \text { hypernatremia }(\mathrm{Na}>145) \\
0 & \text { hypoglycemia }(\mathrm{BS}<50)\end{array}\end{array}$ & $\begin{array}{l}\text { ght.org) and } / o r>=7 \text { tho at } 24 \mathrm{~h} \\
\text { rother clinical si } / 5 x \text { of deh ydration } \\
\text { d) }\end{array}$ \\
\hline
\end{tabular}




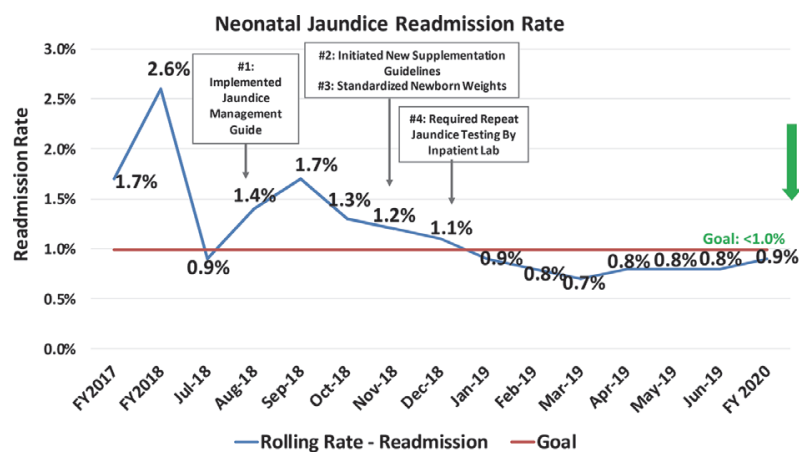

Abstract 19 Figure 3

than accepting lab values from other facilities which were often found to be different (figure 2).

Results Overall, the rolling percentage of neonatal jaundice readmissions for BSWMCW decreased from $2.6 \%$ to $0.8 \%$, meeting the goal of less than $1 \%$. This was sustained through fiscal year 2019 (figure 3).

Conclusions Neonatal Jaundice readmission rates can be affected through standardizing jaundice management protocols. In changing the timing of neonatal weights, this improved neonatal care, even for those without jaundice.

\section{OPTIMIZING INPATIENT SITUATION AWARENESS TO RECOGNIZE AND MITIGATE CLINICAL DETERIORATION IN HOSPITALIZED CHILDREN}

Tina Sosa, Maya Dewan, Michelle Coleman, Brandy Seger, Jackie Hausfeld, Richard Falcone, Patrick Brady, Jeffrey Simmons, Christine White, Mary Sitterding. Cincinnati Children's Hospital Medical Center, USA

\subsection{6/bmjoq-2020-IHI.20}

Background Interventions to improve care team situation awareness (SA) are associated with reduced rates of unrecognized clinical deterioration in hospitalized children. Recent safety events at our institution revealed common etiologic themes, including 1) inadequate SA for patients demonstrating signs of deterioration, and 2) lack of a shared mental model due to inadequate psychological safety and communication.

Objectives We aimed to decrease emergency transfers (ETs) to the intensive care unit (ICU) by $50 \%$ over 10 months.

Methods An interprofessional team of physicians, nurses, respiratory therapists, and families convened to apply innovation to the original SA model for clinical deterioration by addressing emerging corruptors to SA, communication inadequacies, and evolving technology in our inpatient system. Key drivers included establishing a shared mental model, psychologically safe escalation, and efficient and effective SA tools (figure 1). Novel interventions including the intentional inclusion of families and diverse care team roles in huddles, a mental model checklist, door signage, and an electronic health record SA navigator were evaluated via a time series analysis. Sequential inpatient-wide testing of the SA model allowed for iteration and consensus building across care teams and families via qualitative data collection and review. The primary outcome measure was ETs, defined as any ICU transfer where the patient

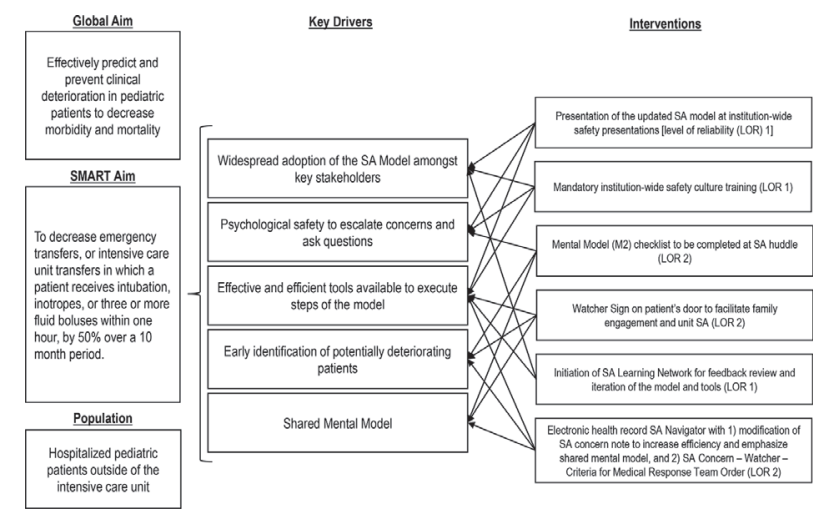

Abstract 20 Figure 1 Key driver diagram for the SA Model for clinical deterioration

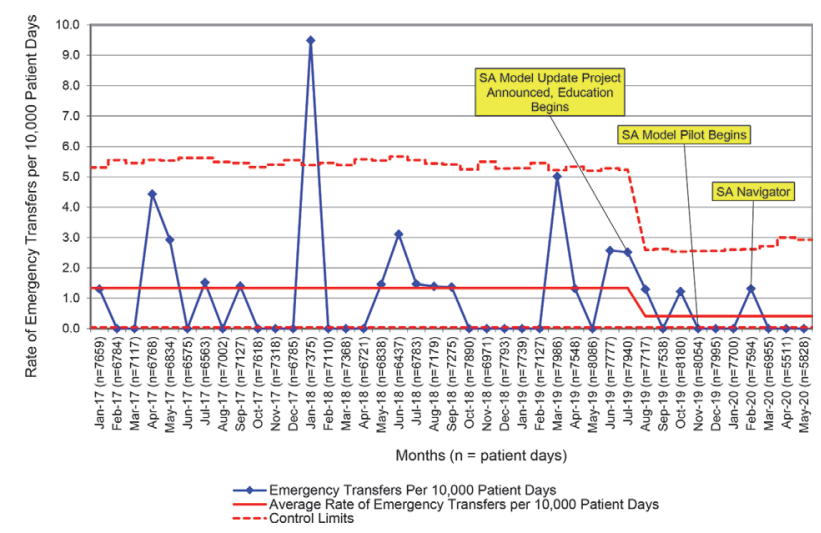

Abstract 20 Figure 2 Outcome measure: emergency transfers. Statistical process control U-chart of the rate of emergenc transfers per 10,000 patient days. Established rules for shewhart control were utilized to determine if observed changes were due to special causes variation
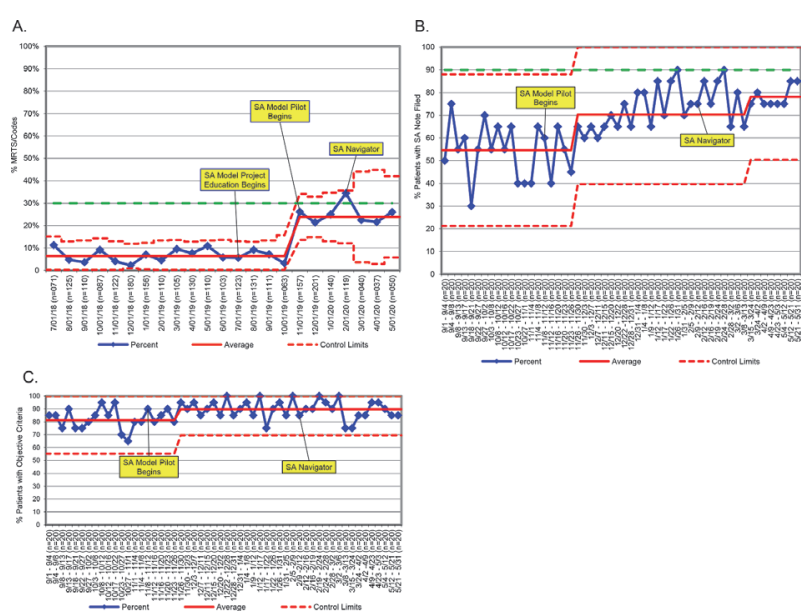

Abstract 20 Figure 3 Process measures. Statistical process control Pcharts: A) Percent of patients designated as watchers at least one hour prior to medical response team or code activation. B) Percent of watcher patients who have an SA note filed within two hours of watcher status initiation. C) Percent of watcher patients who have objective medical response team activation criteria. Established rules for Shewhart control charts were utilized to determine If observed changes were due to special cause variation 